\title{
High Temperature Thermoelectric Properties of the Solid-Solution Zintl Phase $\mathrm{Eu}_{11} \mathrm{Cd}_{6} \mathrm{Sb}_{12-x} \mathrm{As}_{x}(x<3)$
}

Nasrin Kazem¹, Weiwei Xie ${ }^{2}$, Saneyuki Ohno ${ }^{3}$, Alexandra Zevalkink ${ }^{3}$,Gordon J. Miller ${ }^{2}$, G. Jeffrey Snyder ${ }^{3}$, Susan M. Kauzlarich ${ }^{1,4}$

1 - Department of Chemistry, University of California, One Shields Ave., Davis, CA 95616, USA

2 - Department of Chemistry, Iowa State University and the Ames Laboratory, US-DOE Ames, IA 50011, USA

3 - Materials Science, California Institute of Technology, 1200 E. California Boulevard, Pasadena, CA 91125,

USA

4 - e-mail: smkauzlarich@ucdavis.edu

\section{Supporting Information}

TGDSC data for $\mathrm{Eu}_{11} \mathrm{Cd}_{6} \mathrm{Sb}_{12}$

$38.0 \mathrm{mg}$ of $\mathrm{Eu}_{11} \mathrm{Cd}_{6} \mathrm{Sb}_{12-x} \mathrm{As}_{x} x_{\text {syn }}=2$ single crystals were used for TG-DSC analysis under $\mathrm{Ar}$ flow. The mass decreasing by $7.07 \%$ around $600{ }^{\circ} \mathrm{C}$ may attribute to As/Sb evaporation. TGDSC data of $\mathrm{Eu}_{11} \mathrm{Cd}_{6} \mathrm{Sb}_{12}$ shows a mass loss around $650{ }^{\circ} \mathrm{C}$ which may be due to vaporization of $\mathrm{Sb}$.

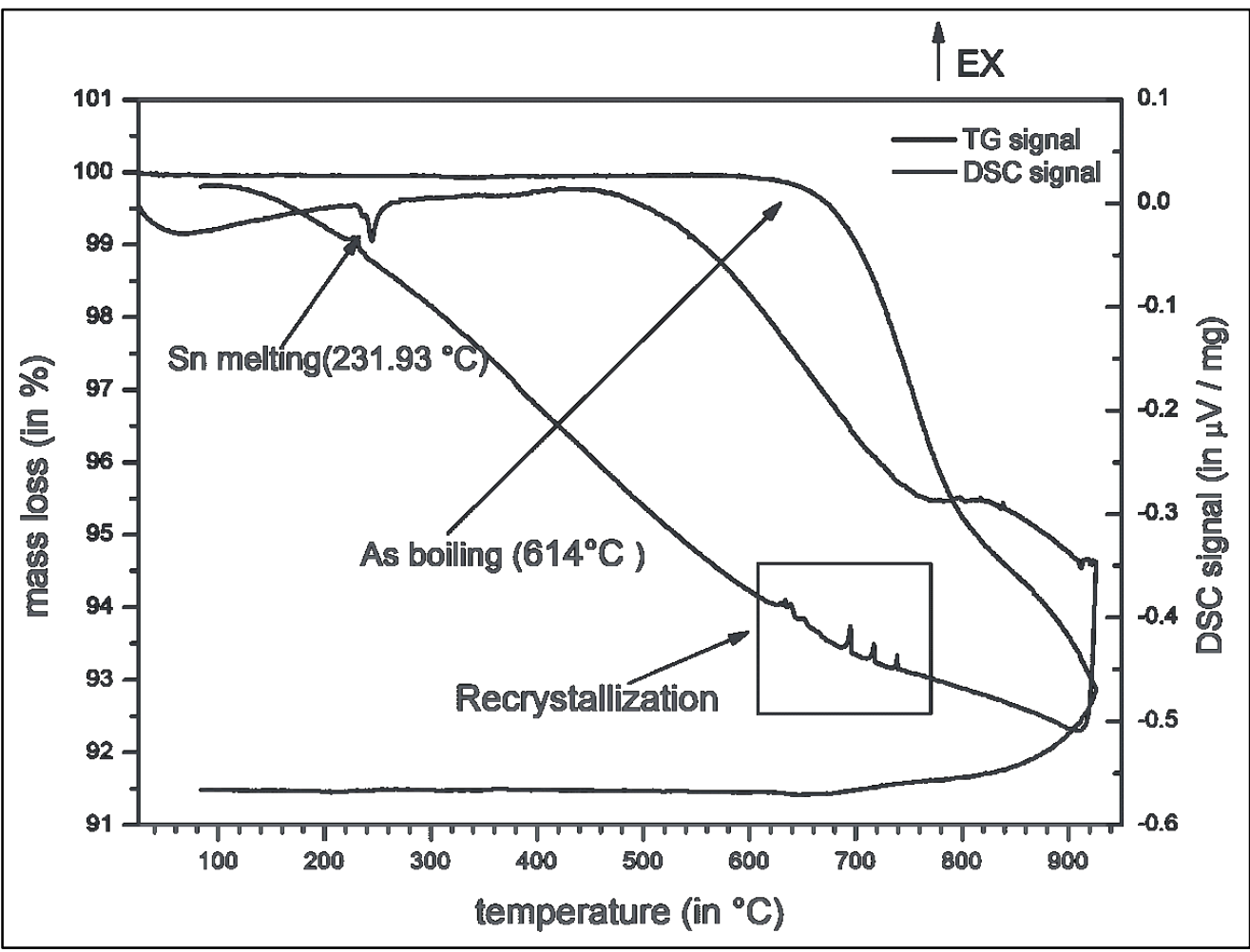

Figure S1. TG_DSC analysis show that there is a mass loss at around 600 which can be attributed to As evaporation. 

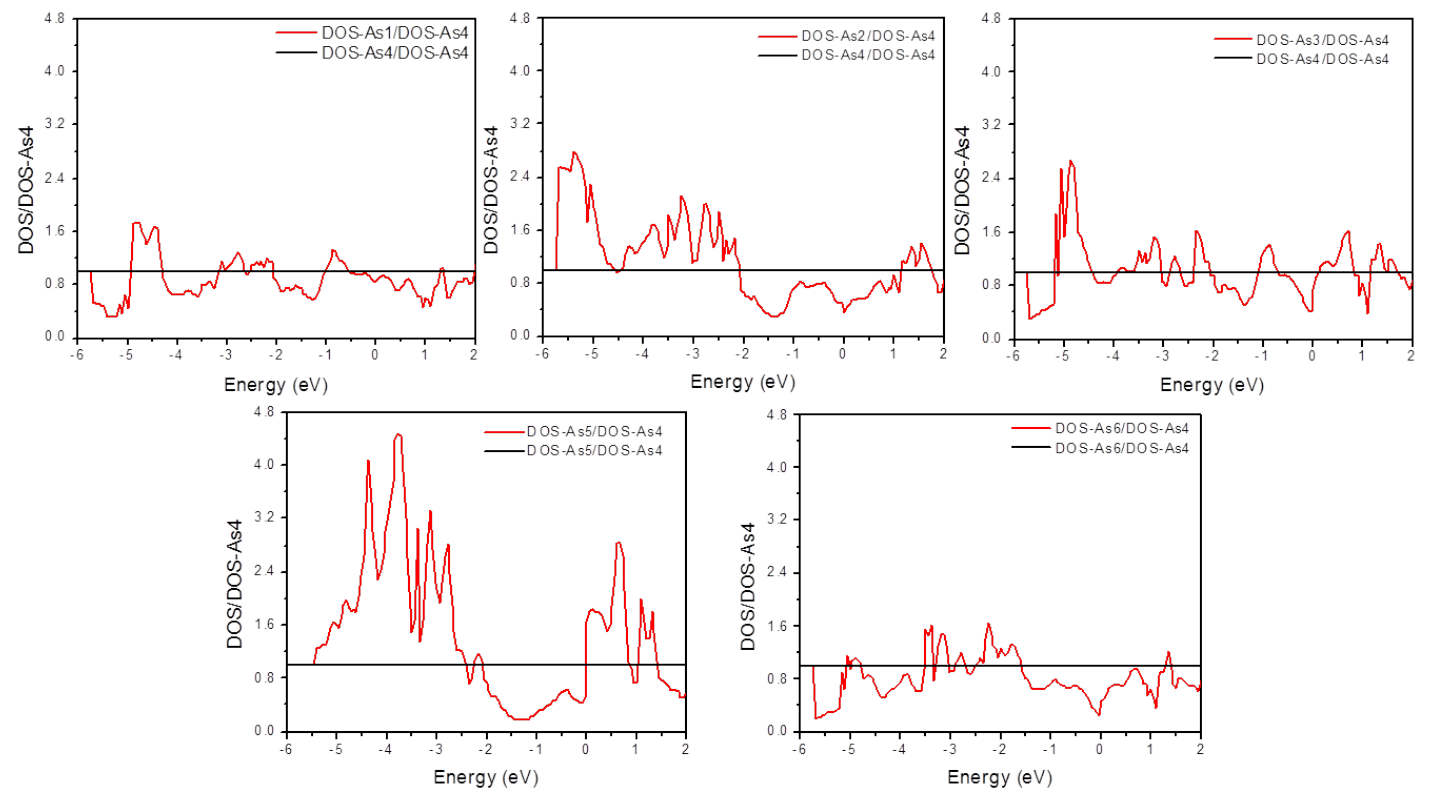

Figure S1. Ratios of As partial DOS curves for sites As1, As2, As3, As5, As6 with respect to the As4 site. The reference line in each graph is 1.00 . When the curve lies above 1.00 , the contribution to the DOS from the site exceeds that from As4; when the curve lies below 1.00, the contribution to the DOS from As4 exceeds that from the given site.

Table S2. Thermal Diffusivity Data for $\mathrm{Eu}_{11} \mathrm{Cd}_{6} \mathrm{Sb}_{12-\mathrm{x}} \mathrm{As}_{\mathrm{x}}(\mathrm{x}=0,1$, and 2)

\begin{tabular}{|c|c|c|c|c|c|c|c|c|}
\hline$x=0$ & Temp. & $\lambda(\mathrm{W} / \mathrm{mK})$ & $x=1$ & Temp. & $\lambda(\mathrm{W} / \mathrm{mK})$ & $x=2$ & Temp. & $\lambda(\mathrm{W} / \mathrm{mK})$ \\
\hline & 352.25 & 0.789942 & & 353.75 & 0.822189 & & 324.85 & 0.833746 \\
\hline & 371.35 & 0.76849 & & 373.75 & 0.80694 & & 372.65 & 0.79669 \\
\hline & 421.45 & 0.716753 & & 423.65 & 0.763733 & & 421.45 & 0.771987 \\
\hline & 474.25 & 0.671325 & & 473.95 & 0.724339 & & 474.15 & 0.738637 \\
\hline & 525.95 & 0.629682 & & 523.95 & 0.663342 & & 525.95 & 0.675643 \\
\hline & 575.65 & 0.619587 & & 574.05 & 0.658259 & & 575.65 & 0.685524 \\
\hline & 625.35 & 0.615802 & & 624.05 & 0.655718 & & 625.35 & 0.694171 \\
\hline & 675.05 & 0.618325 & & 674.05 & 0.655718 & & 675.05 & 0.704052 \\
\hline & 724.85 & 0.627159 & & 724.05 & 0.669696 & & 724.75 & 0.718874 \\
\hline & 774.55 & 0.637254 & & 774.05 & 0.682404 & & 774.65 & 0.732461 \\
\hline & 672.05 & 0.60823 & & 673.55 & 0.645552 & & 672.05 & 0.671937 \\
\hline & 571.15 & 0.601921 & & 573.35 & 0.629032 & & 571.15 & 0.644763 \\
\hline & 469.55 & 0.644825 & & 473.35 & 0.684946 & & 469.55 & 0.674408 \\
\hline & 369.75 & 0.7483 & & 373.65 & 0.766275 & & 369.55 & 0.732461 \\
\hline & 321.95 & 0.811394 & & 323.45 & 0.815835 & & 311.95 & 0.778163 \\
\hline
\end{tabular}

